\title{
Digital Transformation in Property Development and The Role of Change Management: Structured Literature Review and Future Trends
}

\author{
Christian Klee \\ SMBS \\ University of Salzburg Business School \\ Sigmund-Haffner-Gasse 18 \\ A-500 Salzburg
}

\begin{abstract}
Digital transformation affects all areas of business. Some industries are pioneers, whilst others lag behind in implementing digital solutions. The property development business as a traditional business is often neglected in the implementation of digital topics. Consequently, it is a particularly interesting topic to focus on. The paper gives an overview of the current literature on digital transformation and change management and lays bare those areas in the company which are affected, in addition to the role change management plays in the implementation of change processes. Finally, gaps in the research are identified, which may be of interest for future research.
\end{abstract}

Keywords: property developer, digital transformation, empirical study, change management 